\title{
Fácies e Sistema Deposicional da Formação Barreiras na Região da Barreira do Inferno, Litoral Oriental do Rio Grande do Norte
}

\author{
Verônica Dantas de Araúio (veradan@bol.com.br), Yoe Alain Reyes-Peres, \\ Rozileide de Oliveira Lima, Ana Paula de Meireles Reis Pelosi, Leonardo Menezes, \\ Valéria Centurion Córdoba, Francisco Pinheiro Lima-Filho \\ Grupo de Estudo de Análogos a Reservatórios Petrolíferos - Departamento de Geologia - UFRN \\ Av. Senador Salgado Filho s/n - Campus Universitário, CEP 59072-970, Natal, RN, BRA
}

Recebido em 09 de fevereiro de 2006; aceito em 21 de junho de 2006

Palavras-chave: Formação Barreiras, sistemas deposicionais, caracterização faciológica.

\section{RESUMO}

Ao longo da costa brasileira são encontrados depósitos sedimentares atribuídos à Formação Barreiras. No Rio Grande do Norte, estes depósitos ocorrem principalmente na linha de costa, tendo como melhor exemplo a Barreira do Inferno, um afloramento com mais de $1 \mathrm{~km}$ de extensão e até $20 \mathrm{~m}$ de espessura, situado no município de Parnamirim (RN). As associações de fácies descritas foram interpretadas como indicativas da deposição em um contexto fluvial, sendo as de granulação mais grossa relacionadas a depósitos de preenchimento de canais e as de textura mais fina, atribuídas a depósitos de planície de inundação. Estes depósitos mostram lateralmente uma clara diminuição da proporção entre arenitos e conglomerados versus lamitos. Na região que foi interpretada como a porção mais central de um suposto cinturão fluvial, a sucessão apresenta quase $80 \%$ de arenitos e conglomerados, ao passo que, lateralmente, a menos de $200 \mathrm{~m}$, chega a ter $40 \%$ de rochas de granulação mais fina, o que sugere a proximidade da planície de inundação. Apesar de o sistema fluvial interpretado apresentar algumas características de um sistema entrelaçado, a abundância de fácies pelíticas, bem como a ocorrência freqüente de estratos com geometria de preenchimento de canais, permite estabelecer uma maior aproximação a um sistema fluvial meandrante. Considerando esses aspectos, o modelo "Meandrante de Granulometria Grossa” é o que melhor representa estes depósitos.

Keywords: Barreiras Formation, fluvial systems, facies analysis.

\section{ABSTRACT}

The Barreiras Formation is composed of sedimentary siliciclastic rocks that crop out at the continental scale along the Brazilian coastline from the State of Rio de Janeiro to the State of Amapá. In the State of Rio Grande do Norte, this formation is well exposed in cliffs along the coastline, best represented by the Barreira do Inferno cliff, which is $1 \mathrm{~km}$ long and $20 \mathrm{~m}$ high. Facies characterization and interpretation of depositional systems of the Barreiras Formation in this cliff were based on stratigraphic columnar sections and digital photomosaics. The Barreira do Inferno cliff comprises a large area affording continuous exposure of bed geometries, generally tabular in shape with secondary channels filled by mudstones, indicative of a fluvial context. Coarse facies characterize channel environments, whereas fine facies represent flood plains. This interpretation is supported by a lateral decrease in the ration of sandstone/conglomerates versus mudstones along the outcrop. In the central portion of the fluvial belt, sands and conglomerates comprise up to $80 \%$ of the deposits. Laterally, in the flood plain, up to $40 \%$ of the deposits are mudstones, fine sands, and very fine sands. This system is similar to braided fluvial systems, but the facies association (with pelites) and layer geometries (abandoned channels filled by mudstones) are characteristic of meandering rivers. The model that best explains these deposits is the "coarse-grained meandering river model". 


\section{INTRODUÇÃO E CONTEXTO GEOLÓGIÇO REGIONAL}

A Formação Barreiras constitui a unidade geológica de ocorrência mais expressiva da costa brasileira, aflorando desde o Estado do Rio de Janeiro até o Amapá. Estes depósitos vêm sendo estudados por diversos pesquisadores, alguns dos quais, mais recentemente, chamaram atenção para a necessidade de caracterização das suas fácies, visando uma melhor interpretação dos sistemas deposicionais envolvidos e sua correlação regional. Assim, o presente trabalho tem como objetivo a caracterização faciológica das rochas da Formação Barreiras na região da Barreira do Inferno, no município de Parnamirim, litoral oriental do Rio Grande do Norte.

Os estudos pioneiros datam do início do século $\mathrm{XX}$, quando Branner (1902, apud Mabesoone et al., 1972) fez a primeira referência a esta unidade. Nas décadas seguintes, citam-se os trabalhos de Moraes (1924) e Oliveira e Leonardos (1943), que denominaram de "Série das Barreiras" e, a partir de Kegel (1957), esta unidade passou à categoria de formação.

Bigarella e Andrade (1964), ao estudarem a faixa costeira do Estado de Pernambuco, redefiniram esta unidade como Grupo Barreiras e propuseram duas novas formações: a inferior, chamada Guararapes e, a superior, denominada de Riacho Morno.

Campos e Silva (1966) distinguiram, na região entre Natal e Macaíba (RN), duas outras unidades superpostas à Formação Riacho Morno, denominadas de formações Macaíba e Potengi, não tendo sido identificada a Formação Guararapes de Bigarella e Andrade (1964).

Mabesoone et al. (1972), baseados em dados de afloramentos e de subsuperfície, redefiniram o Grupo Barreiras (sensu Bigarella e Andrade, 1964) na região entre o Rio Grande do Norte e Pernambuco, dividindo-o nas formações Serra do Martins, Guararapes e Macaíba. As propostas de trabalhos anteriores, onde foram individualizadas as formações Guararapes e Riacho Morno, foram refutadas, sugerindo que a Formação Riacho Morno seria apenas um manto de intemperismo da Formação Guararapes. O mesmo foi sugerido para a unidade Potengi, a qual corresponderia a um manto de intemperismo ferruginoso da Formação Macaíba, ocorrendo de forma descontínua. A Formação Serra do Martins, por outro lado, teria sua ocorrência restrita ao topo das chapadas interioranas, apresentando uma capa laterítica composta por arenitos ferruginosos, denominados de Intemperismo Laterítico. Mabesoone et al. (1972) concluíram ainda que a origem dos litotipos do Grupo Barreiras estaria associada à formação de espessos solos lateríticos, desenvolvidos em épocas de relativa estabilidade tectônica e climática.
A remoção destes mantos intempéricos e a erosão de rochas subjacentes teriam permitido a redeposição como sedimentos das formações Serra do Martins, Guararapes e Macaíba.

Bigarella (1975), realizando uma revisão sobre os aspectos morfológicos e estratigráficos do Grupo Barreiras, excluiu a Formação Macaíba, tratando-a como uma unidade independente, possivelmente correlacionável à Formação Serra do Martins, segundo a divisão anterior de Bigarella e Andrade (1964).

Em trabalhos mais recentes, as rochas designadas de "Barreiras" foram reposicionadas na categoria de formação por Mabesoone et al. (1991). As unidades antes individualizadas representariam, segundo esses autores, apenas variações faciológicas dos diferentes sistemas deposicionais associados, corroborando a concepção estabelecida anteriormente por Kegel (1957).

Suguio e Nogueira (1999) realizaram uma revisão crítica do conhecimento geológico acerca da Formação Barreiras, enfatizando que a caracterização faciológica associada à aplicação dos conceitos de Estratigrafia de Seqüência é de fundamental importância para a reconstrução paleogeográfica desta unidade sedimentar.

Trabalhos que ressaltam estes aspectos foram desenvolvidos a partir do final dos anos 80, quando Rossetti (1988) sugeriu que as rochas da Formação Barreiras, na porção nordeste do Estado do Pará, teriam sido depositadas como leques aluviais, com provável influência de marés na porção mais distal do sistema. Outros autores (Arai et al., 1988; Arai, 1997), também em estudos na área supracitada, reforçaram a idéia da contribuição marinha, baseados na presença de gêneros de dinoflagelados e de restos quitinosos de microforaminíferos.

Alheiros et al. (1988) e Alheiros e Lima-Filho (1991) realizaram mapeamentos geológicos na região entre o Rio Grande do Norte e Pernambuco e concluíram que as rochas sedimentares da Formação Barreiras teriam sido depositadas em um ambiente fluvial entrelaçado, associado a leques aluviais e a depósitos litorâneos.

Menezes et al. (1998) analisaram afloramentos às margens do Rio Curimataú, em Canguaretama (litoral leste do Rio Grande do Norte), e os interpretaram como um sistema fluvial meandrante com influência estuarina. VilasBoas et al. (2001), em estudo de sucessões sedimentares correlatas à Formação Barreiras na região de Conde (BA), propuseram que os litotipos presentes foram depositados por um sistema fluvial entrelaçado, associado a leques aluviais de clima árido a semi-árido. Sousa (2002) e Morais et al. (2005) também reconheceram um paleoambiente fluvial entrelaçado na sedimentação das fácies encontradas respectivamente na região de Icapuí (CE) e no Estado do Rio de Janeiro (RJ). 


\section{CARACTERIZAÇÃO FACIOLÓGICA}

Na região litorânea do Rio Grande do Norte, entre Parnamirim e Nísia Floresta, a Formação Barreiras apresenta os melhores afloramentos em falésias, como na Ponta do Cotovelo (Barreira do Inferno), na Ponta do Flamengo e na Ponta de Tabatinga (Figura 1). À exceção das ocorrências em falésias, foram identificadas rochas desta unidade litoestratigráfica em cortes de estradas e na margem de rios. Entretanto, tais litotipos encontram-se intensamente intemperizados, dificultando a análise faciológica como, por exemplo, os que ocorrem próximos à margem do Rio Pirangi, em Nísia Floresta $(\mathrm{RN})$.

São encontradas ainda exposições da Formação Barreiras distantes da costa, capeadas por crostas lateríticas, como na praia de Pirangi, onde são observáveis somente nas marés baixas de sizígia.

O afloramento estudado localiza-se na praia de Cotovelo, apresentando uma área com exposição lateral descontínua de aproximadamente $2,5 \mathrm{~km}$, com altura variável, atingindo até $20 \mathrm{~m}$ na parte central da Barreira do Inferno. Foram individualizadas três fácies principais, denominadas de Gt, St e Fl. A fácies Gt reúne as rochas de textura mais grossa descritas na área e corresponde a conglomerados sustentados por matriz arenosa, com estratificação cruzada acanalada de grande a médio porte e, subordinadamente, conglomerados clastos suportados. No seu arcabouço predominam seixos de quartzo, feldspatos e clastos de argila. A cimentação

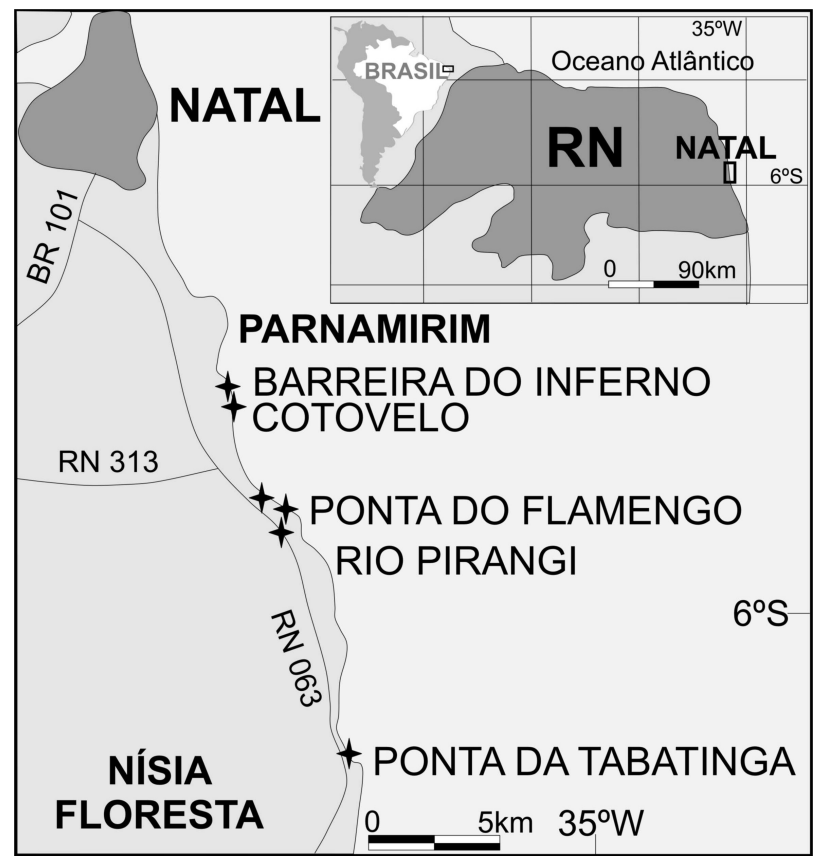

Figura 1. Principais afloramentos de rochas da Formação Barreiras na região entre Parnamirim e Nísia Floresta (indicados pelo símbolo + ). ferruginosa confere a estas rochas uma cor avermelhada. Os seixos de quartzo, com até $6 \mathrm{~cm}$ (eixo maior), são subangulosos a subarredondados e exibem baixa esfericidade; ocorrem subordinadamente seixos bem arredondados, com alta esfericidade (Figura 2A). Os grãos de feldspatos são subangulosos e de baixa esfericidade, com o eixo maior atingindo até $2 \mathrm{~cm}$. Os clastos de argila são bem arredondados e de baixa esfericidade, com eixo maior chegando a $10 \mathrm{~cm}$. Os variáveis estágios de maturidade dos seixos sugerem a existência de mais de um ciclo de sedimentação e retrabalhamento. Entretanto, pode-se afirmar que, no geral, a fácies mostra uma baixa maturidade mineralógica, evidenciada pela existência de uma grande quantidade de seixos de feldspatos. As rochas representadas por esta

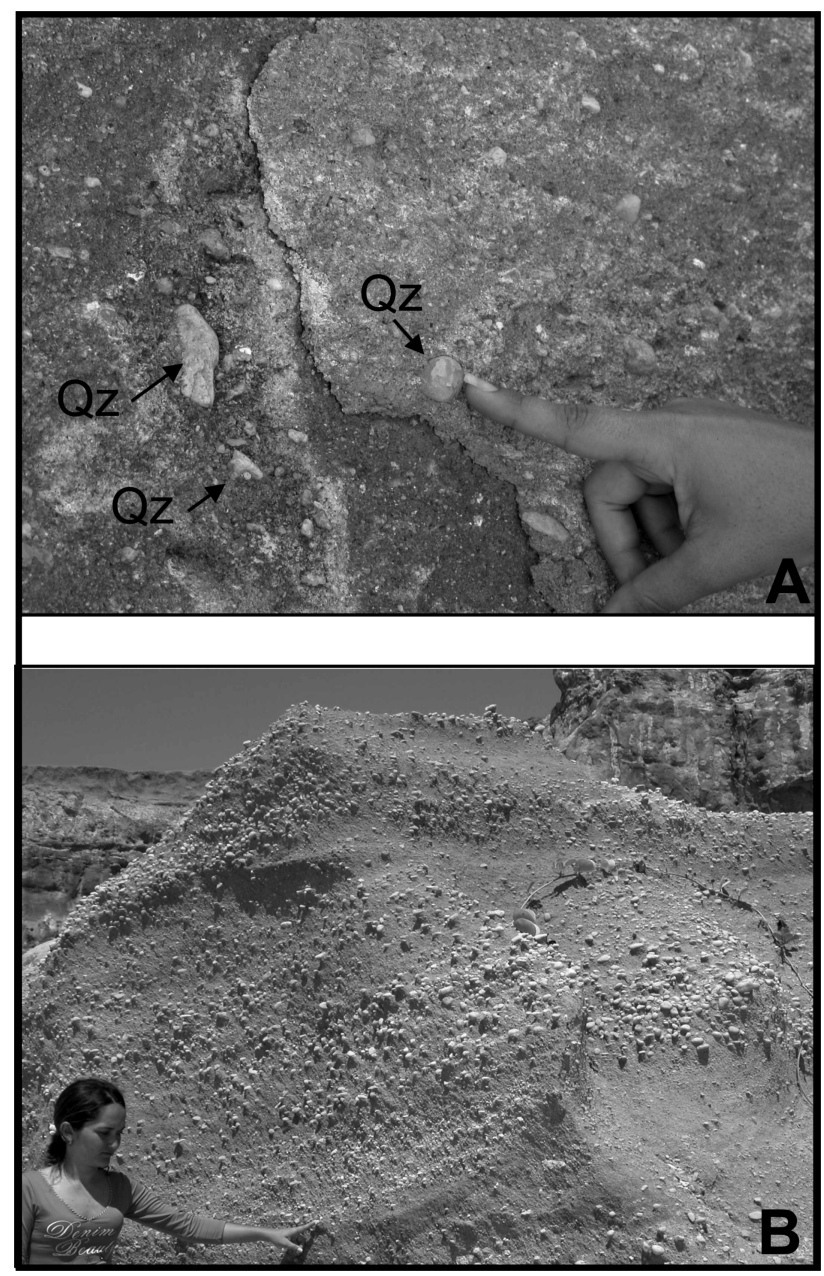

Figura 2. Fácies Gt no afloramento da Barreira do Inferno. A. Detalhe do arcabouço da rocha, mostrando grãos de quartzo $(\mathrm{Qz})$ com variações texturais, indicando estágios distintos de maturidade. B. Conglomerados organizados mostrando estratificação cruzada acanalada. As camadas frontais são marcadas por níveis de seixos. 
fácies dispõem-se em estratos com espessuras de até 1,5 m, onde os planos frontais são definidos principalmente por seixos de quartzo (Figura 2B). Esta fácies foi interpretada como sendo gerada pela migração de formas de leito de crista sinuosa (3D), que apresentam espessuras variando de 0,4 a 1,5 m e extensão lateral na ordem de poucas dezenas de metros. A fácies Gt ocorre sempre associada à fácies $\mathrm{St}$, ocupando preferencialmente os níveis mais basais das barras, sendo comum nestes níveis a presença dos maiores clastos de pelitos.

A fácies St é representada por arenitos de textura muito grossa, grossa e média, de coloração amarelada, exibindo estratificação cruzada acanalada e subordinadamente tabular, mostrando eventualmente seixos dispersos. As estratificações cruzadas estão marcadas principalmente por seixos ou grânulos de quartzo. Clastos de argila são raros. Esta fácies caracteriza-se por exibir estratificação cruzada, de pequeno a médio porte, interpretada como resultante da migração de formas de leitos 3D, com sets de 15 a $30 \mathrm{~cm}$ de espessura. Predomina a geometria tabular, gerada pelo truncamento sucessivo das formas de leito, com espessuras da camada de até $2 \mathrm{~m}$, em contato erosivo com a fácies $\mathrm{Gt}$ e abruptos com a Fl (Figura 3). Esta fácies ocorre sobreposta por lamitos (Fácies $\mathrm{Fl}$ ).

A fácies Fl compreende lamitos com diferentes proporções de argila, silte e areia mostrando coloração avermelhada, com intercalação de arenito fino e muito fino. É constituída por uma lama argilosa cimentada por óxido de ferro com grãos de quartzo que ocorrem flutuantes na matriz lamosa, de granulometria síltica até, excepcionalmente, areia média, sendo subangulosos a subarredondados. Exibe laminações plano-paralelas e bioturbações, estas últimas possivelmente geradas pela ação de organismos invertebrados e de raízes de vegetais superiores. Os estratos

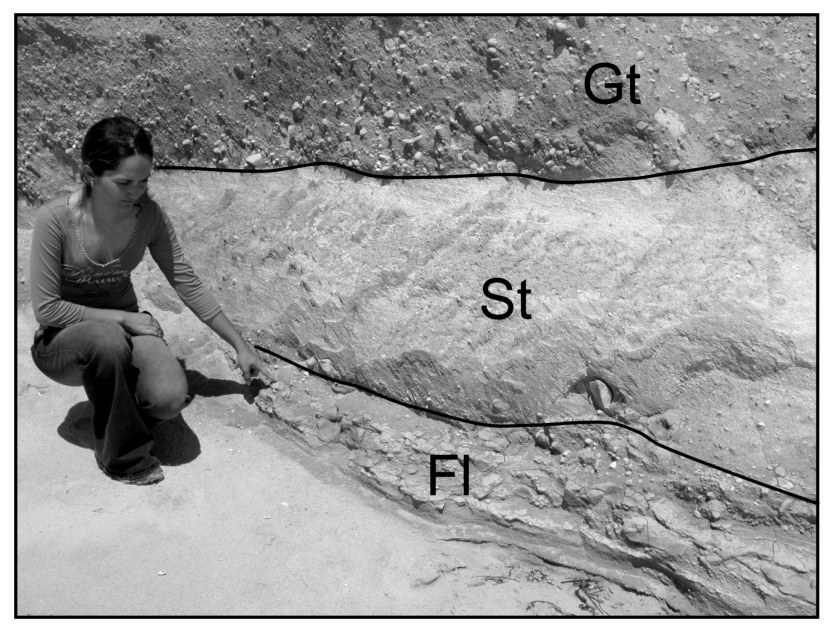

Figura 3. Relações de contato entre as fácies Gt, St e Fl. apresentam geometria de canal, com dimensões que chegam a $1 \mathrm{~m}$ de espessura e $15 \mathrm{~m}$ de extensão (Figura 4), como também geometria tabular com continuidade lateral de mais de $200 \mathrm{~m}$. Os corpos tabulares apresentam variação de espessura desde poucos centímetros, quando ocorrem subordinadas às fácies $\mathrm{Gt} \mathrm{e} \mathrm{St}$ (podendo até desaparecer), e podem atingir espessuras da ordem de 2,3 $\mathrm{m}$ (Figura 5).

\section{INTERPRETAÇÃO PALEOAMBIENTAL}

A partir do empilhamento vertical das fácies Gt, St e Fl e da correlação das mesmas ao longo do afloramento, foi possível individualizar ciclos de afinamento textural para o topo, os quais se correlacionam muito bem com o modelo de fácies para sistemas fluviais proposto por Walker e Cant (1984). Com base na descrição e interpretação das fácies, foi possível compartimentar os depósitos fluviais identificados nas escarpas da Barreira do Inferno em dois grupos:

1. depósitos de preenchimento de canal;

2. depósitos de planície de inundação.

Os depósitos de preenchimento de canal são representados pelas fácies $\mathrm{Gt} \mathrm{e} \mathrm{St,} \mathrm{compreendendo} \mathrm{conglomerados,}$ arenitos grossos a muito grossos e arenitos médios, mostrando estratificação cruzada acanalada, tabular e gradação normal. Eventualmente esta fácies ocorre também na forma maciça exibindo apenas gradação normal. Os conglomerados clastos suportados podem ser relacionados a depósitos do tipo "lag" residual, enquanto os conglomerados suportados por matriz arenosa, arenitos conglomeráticos e arenitos grossos a muito grossos podem corresponder a depósitos de preenchimento de canal gerados pela migração de barras longitudinais. Já os arenitos de textura grossa

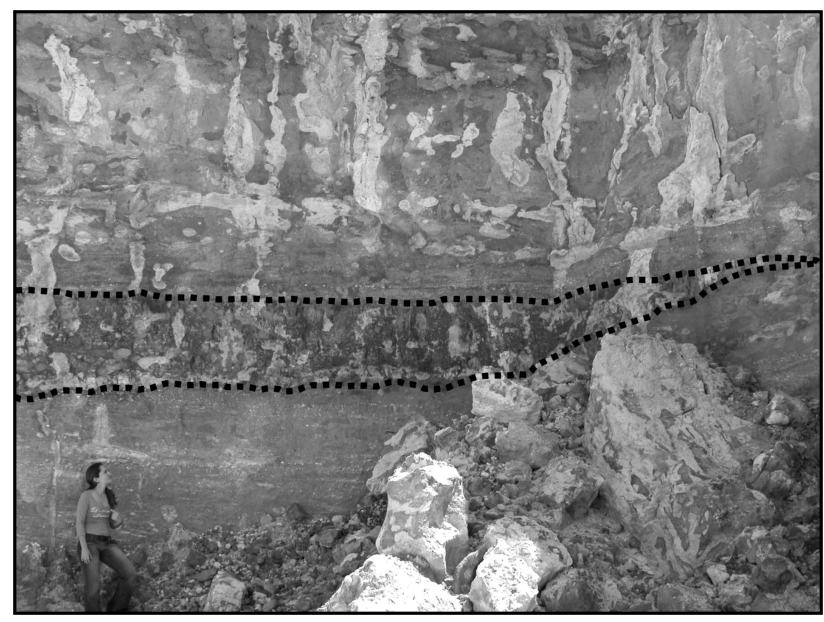

Figura 4. Fácies Fl disposta em geometria de canal. 


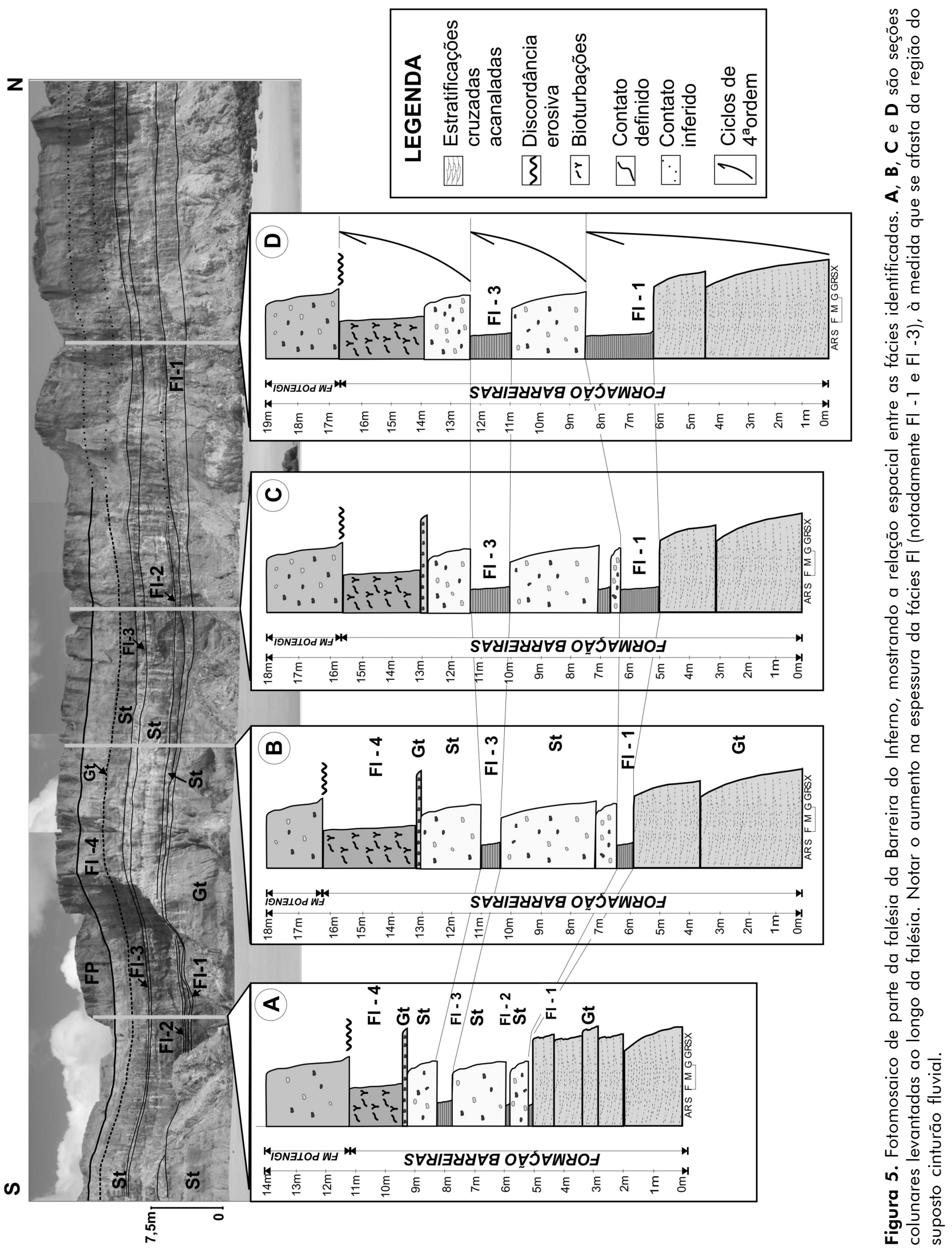


e média com cruzadas acanaladas e tabulares podem representar barras de acreção frontal e lateral. Os depósitos de planície de inundação são caracterizados por pacotes de lamitos bioturbados e laminados, intercalados com arenitos finos a médios representados conjuntamente pela fácies Fl. Nesta fácies estão representados também depósitos de abandono de canal, como meandros abandonados que permaneceram cobertos de água (chute cut off), favorecendo a colonização por organismos responsáveis pela grande quantidade de bioturbação. Tais bioturbações podem ter mascarado completamente qualquer estrutura sedimentar primária existente. A presença de vegetação, com raízes, na planície de inundação também pode ser responsável pela bioturbação identificada em alguns níveis pelíticos.

Foram reconhecidos pelo menos cinco ciclos fluviais incompletos, separados por superfícies limitantes (sensu Miall, 1988) de $4^{\mathrm{a}}$ ordem, relacionados a depósitos de preenchimento e transbordamento de canal. Os ciclos mostram continuidade lateral na ordem de centenas de metros provavelmente devido a fatores autocíclicos como, por exemplo, reativações do canal fluvial, causados por variações sazonais. Na região mais central do cinturão fluvial, em virtude do processo de erosão e amalgamento das barras fluviais, os ciclos tendem a ser incompletos e apresentam, em geral, as menores espessuras $(0,8$ a $5 \mathrm{~m})$. Lateralmente, quando se avança em direção à planície de inundação, os ciclos passam a conter uma porção pelítica maior (níveis, como o Fl-1, passando de $0,20 \mathrm{~m}$ para aproximadamente 2,3 m; Figura 5) e tendem a ser mais completos (atingindo até $8 \mathrm{~m}$ de espessura).

Apesar da associação de fácies acima descrita mostrar características de um sistema fluvial meandrante, com identificação de supostos depósitos de canal fluvial e de planície de inundação, a quantidade de fácies de granulação fina normalmente encontrada neste sistema é maior que aquela aqui identificada. Em contrapartida, há muita rocha pelítica para um típico sistema fluvial entrelaçado. Dessa forma, optou-se por enquadrar o sistema fluvial interpretado para a área estudada como modelo intermediário do tipo "Meandrante de granulometria grossa", termo proposto por Brown et al. (1973).

Os litotipos da Formação Barreiras são freqüentemente interpretados como sistemas deposicionais de leque aluvial e fluvial entrelaçado, em ambiente continental. Tais sistemas são bastante citados na literatura e por vezes associados à presença de clima árido ou semi-árido que controlava as condições deposicionais. Obviamente que as condições climáticas restritas favorecem o desenvolvimento destes sistemas. Entretanto, a presença de microclimas ou mesmo outras condições específicas, que envolvam rios com baixo gradiente, podem permitir a deposição de sedimentos pelíticos em regiões próximas à linha de costa. Tal contexto foi também concebido por Menezes et al. (1998), no litoral leste do Rio Gran- de do Norte, em afloramentos situados no município de Canguaretama. Estes autores reportam também a presença de sedimentação estuarina naquela área estudada.

A separação entre depósitos estuarinos e fluvial meandrante é geralmente difícil e controvertida, principalmente quando a amplitude de maré é pequena. Neste caso, tende a prevalecer os depósitos com características fluviais, independentemente do gradiente do rio próximo à região de desembocadura. Não está descartada a possibilidade de se encontrar elementos que pudessem levar à interpretação de eventuais sistemas parálicos na região da Barreira do Inferno, entretanto, acredita-se que estes devam ter sido depositados numa posição mais distal, provavelmente erodidos durante o recuo da falésia.

\section{AGRADECIMENTOS}

À ANP, à CAPES e ao CNPq, pelas bolsas concedidas aos integrantes do GEA (Grupo de Estudo de Análogos a Reservatórios Petrolíferos - UFRN). À PETROBRÁS, à FUNPEC e à FINEP, pelos auxílios financeiros. Aos revisores Prof. Dr. Kenitiro Suguio, Prof. Dr. Claudio Limeira Mello e Prof. Dr. Francisco Hilário Rego Bezerra, pelas sugestões ao manuscrito.

\section{REFERÊNCIAS BIBLIOGRÁFICAS}

ALHEIROS, M. M.; LIMAFILHO, M. F. A Formação Barreiras. Revisão geológica da Faixa Sedimentar Costeira de Pernambuco, Paraíba e Rio Grande do Norte. Estudos Geológicos (Série B Estudos e Pesquisas), v. 10, p. 77-88, 1991.

ALHEIROS, M. M. et al. Sistemas deposicionais na Formação Barreiras no Nordeste Oriental. In: CONGRESSO BRASILEIRODEGEOLOGIA, 35.,1988, Belém. Anais...Belém: SBG 1988. v. 2, p. 753-760.

ARAI, M. Dinoflagelados (Dinophyceae) miocênicos do Grupo Barreiras no nordeste de Estado do Pará (Brasil). Revista Universidade Guarulhos, Geociências, ano 2, p. 98-106, 1997. Número especial.

ARAI, M.; et al. Considerações sobre a idade do Grupo Barreiras no nordeste do Estado do Pará. In: CONGRESSO BRASILEIRODEGEOLOGIA, 35.1988. Belém. Anais...Belém: SBG 1988.v. 2, p. 738-752.

BIGARELLA, J. J. The Barreiras Group in northeastern Brazil. Anais da Academia Brasileira de Ciências, v. 47, p. 365-393, 1975. Suplemento.

BIGARELLA, J. J.; ANDRADE, G. O. Considerações sobre a 
estratigrafia dos sedimentos cenozóicos em Pernambuco (Grupo Barreiras). Arquivos do Instituto Ciências da Terra, v. 2, p. 1-14, 1964.

BROWN, L. F.; CLEAVES, A. W.; ERXLEBEN, A. W. Pennsylvanian depositional systems in North-central Texas. Bureau Economic Geology, v. 14, p. 1-122, 1973. Guidebook.

CAMPOS E SILVA, A. Considerações sobre o Quaternário no Rio Grande do Norte. Arquivo do Instituto de Antropologia, Natal, v. 2, p. 275-301, 1966.

KEGEL, W. Contribuição ao estudo da Bacia Costeira do Rio Grande do Norte. Rio de Janeiro: DGM, 1957. 52 p. (Boletim da Divisão de Geologia e Minerologia, 170).

MABESSOONE, J. M.; CAMPOS E SILVA, A.; BEURLEN, K. Estratigrafia e Origem do Grupo Barreiras em Pernambuco, Paraíba e Rio Grande do Norte. Revista Brasileira de Geociências, v. 2, n. 3, p. 173-178, 1972.

MABESOONE, J. M. (Coord.). Revisão geológica da faixa sedimentar costeira de Pernambuco, Paraíba e parte do Rio Grande do Norte. Estudos Geológicos (Série B, Estudos e Pesquisas), v. 10, 252 p., 1991.

MENEZES, M. R. F. et al. Discordâncias e inundações no Grupo Barreiras, litoral leste do Rio Grande do Norte. In: CONGRESSO BRASILEIRODE GEOLOGIA, 50.,1998, Belo Horizonte. Anais...Belo Horizonte: SBG 1998. p. 75.

MIALL, A. D. Reservoir heterogeneities in fluvial sandstone lessons from outcrop studies. American Association of Petroleum Geologists Bulletin, Tulsa, v. 72, n. 6, p. 684-697, 1988.

MORAES, L. J. Serras e montanhas do nordeste. Rio de Janeiro, 1924. 1077 p. (Coleção Mossoroense, 35).

MORAIS, R. M. O. et al. Fácies sedimentares e ambientes deposicionais associados a depósitos da Fm Barreiras no Estado do Rio de Janeiro. In: CONGRESSO DA ASSOCIAÇÃO BRASILEIRA DE ESTUDOS DO QUATERNÁRIO, 10., 2005, Guarapari. Anais... Guarapari: ABEQUA, 2005. (CD ROM).

OLIVEIRA, A. I.; LEONARDOS, O. H. Geologia do Brasil. Rio de Janeiro: Serviço Informação Agrícola/Ministério da Agricultura, $1943.813 \mathrm{p}$.

ROSSETTI D. F. Reconstituição paleoambiental do Grupo Barreiras no Nordeste do Pará. Brasília: CNPq - Aperfei- çoamento Científico, 1988. 84 f. (Relatório final).

SOUSA, D. C. Litoestratigrafia e deformação cenozóica na região de Icapuí, Ceará, e implicações para a Estruturação de Campos de Petróleo na Borda Ocidental da Bacia Potiguar (NE do Brasil). 2002. 189 f. Tese (Doutorado) - Programa de Pós Graduação em Geodinâmica e Geofísica - PPGG, Universidade Federal do Rio Grande do Norte, Natal, 2002.

SUGUIO, K.; NOGUEIRA, A. C. R. Revisão crítica dos conhecimentos geológicos sobre a Formação (ou Grupo?) Barreiras do Neógeno e o seu possível significado como testemunho de alguns eventos geológicos mundiais. Geociências, São Paulo, v. 18, p. 461-479, 1999.

VILAS BOAS, G.; SAMPAIO, F. J.; PEREIRA, A. M. S. The Barreiras Group in the Northeastern coast of the State of Bahia, Brazil: depositional mechanisms and processes. Anais da Academia Brasileira de Ciências, Rio de Janeiro, v. 73, n. 3, p. 417-427, 2001.

WALKER, R. G.; CANT, D. J. Sandy fluvial systems. In: WALKER, R. G. (Ed.). Facies model 2. ed.,Toronto, 1984. p. 71-89. (Geoscience Canada Reprint Series, 1). 